\title{
O crioulo haitiano e o seu reconhecimento político*
}

\section{Haitian creole and its political recognition}

Marília Lima Pimentel ${ }^{1}$ Geraldo Castro Cotinguiba ${ }^{2}$ Ailton Artur da Silva Ribeiro ${ }^{3}$
Recebido em: 15/03/2016.

Aprovado em: 14/04/2016.

1 Doutora em Linguística e professora do Departamento de Letras Vernáculas da Universidade Federal de Rondônia - UNIR.E-mail: mpimentel9@ gmail.com.

2 Doutorando em Desenvolvimento Regional e Meio Ambiente e professor do Departamento de Ciências Sociais da Universidade Federal de Rondônia - UNIR.E-mail: gcotinguiba@gmail. com.

3 Mestrando em Letras pela Universidade Federal de Rondônia (UNIR). Membro do grupo de Estudos MIMCAB. Bacharel e Mestre em Teologia pelo Seminário Adventista Latino Americano de Teologia (SALT-BA). E-mail: aifupascv@gmail.com.

\section{Resumo}

O presente trabalho tem como objetivos demonstrar como a língua, de um modo geral, é dominada e contornada pelos interesses e práticas políticas da elite de uma sociedade, tornando-se um meio político de dominação e inibidor de oportunidade e espaço sociais. Também identificar os desafios que o crioulo haitiano enfrentou no seu processo de oficialização; analisar, criticamente, a relação de poder envolvida no processo de padronização e oficialização de uma língua como discurso dominante sobre as classes menos favorecidas. Pôde-se constatar que o Haiti permanece uma colônia mesmo após mais de duzentos anos de independência, pelo menos política, cultural e linguisticamente. A ideologia e os discursos colonialistas das elites racial, política e econômica continuam a ser reproduzidos. Como resultado, ao longo dos anos, lutas têm sido travadas para que a identidade histórica, cultural e linguística não morresse, mas fosse dada vida e voz por meio de atitudes políticas e sociais.

Palavras-chave: Oficialização. Créole Haitiano. Haiti. Identidade.

\begin{abstract}
The present research has as goal to demonstrate how the language is dominated and contoured by the interests and politics practices of the elite of a society, becoming a politic instrument of domination and inhibition to the social opportunities. Therefore, it intends to identify the challenges the Haitian's Créole faced in its process of formalization; Analyze critically the relation of power involved in the process of the patronization and formalization of a language as a dominant discourse upon the subordinate classes. We could comprehend that the Haiti remain living as a colonial country, although, more than two hundred years after its independence, at less, politic, cultural and linguistically. The colonialist ideology and discourses of the racial, politic and economic elites remains being reproduced. As a results, throughout the years, many battles have been struggled, aiming not leave the historic, cultural and linguistic identity die, but, giving them life and voice through the politics and social initiatives.
\end{abstract}

Keywords: Formalization. Haitian Créole. Haiti. Identity. 


\section{Apresentação}

As origens do crioulo haitiano podem ser levantadas, mas o seu início é uma incógnita e, provavelmente, insondável. Não é uma novidade em si tratando do surgimento de uma língua e nem é o objetivo final deste artigo, pois seria uma empreitada extremamente árdua e, certamente, infrutífera. Porém, neste caso, o que podemos afirmar é que estamos a falar de um vernáculo de uma população majoritariamente negra e de origem dupla. Lá, na África de outrora, livre, no Caribe escrava, que se emancipou, se libertou de seus dominadores por conta própria, por meio de suas forças próprias e de seus espíritos ancestrais, por uma revolução. O crioulo é a língua da revolução que instituiu, de um só golpe, três feitos históricos, a primeira república negra da humanidade, a primeira libertação dos escravos negros do mundo colonial e a primeira nação formada por ex-escravos.

Após aproximadamente doze anos de revoltas e batalhas, os negros que entrariam para a história como os haitianos, fizeram capitular a então poderosa França de Napoleão, afugentaram a Espanha e a Inglaterra e, dessa forma, amedrontaram inúmeros senhores de engenho das Américas, especialmente no Brasil, que fez surgir o termo haitianismo no léxico da língua portuguesa. Segundo Carlos Eugênio Líbano Soares e Flávio Gomes (2002), o termo haitianismo se tornou sinônimo de sedições, revoltas, ideias revoltosas de negros. No contexto da revolução haitiana, na virada do século XVIII para o XIX, o crioulo já era uma língua em ascensão. Hoje, no século XXI, é o crioulo mais falado do mundo, com mais de dez milhões de falantes, residentes no Haiti e em diferentes países, dentre eles, mais recentemente, o Brasil.

A língua é um processo cultural, um aspecto constitutivo de um povo em qualquer sociedade. Não se adquire na escola, tampouco depende dos projetos de alfabetização ou letramento para ser adquirida. Ao contrário, é fruto da interação do ser humano com o outro e da sua necessidade de se comunicar e 'contracenar' com o 'outro' no espaço social.

Uma vez que a língua é um produto social, contornado por práticas ideológicas e discursos políticos, surge o questionamento de qual a real necessidade ou interesse social para a oficialização ou não de uma língua? No presente estudo, debateremos os interesses políticos envolvidos no processo de oficialização ou não de uma ou mais línguas dentro de uma sociedade. Nesse caso específico, consideraremos o processo de oficialização do crioulo haitiano como vítima do reinado ditatorial do imperialismo francês mesmo após a independência do Haiti. Ademais, intentamos apresentar um panorama histórico da formação do crioulo haitiano e, para isso, discutiremos a relação de proximidade entre essa língua frente à primeira língua oficial do país, o francês.

$\mathrm{O}$ estudo desse tema que envolve o jogo de interesses da elite socioeconômica e política sobre as massas populacionais, tendo a língua como objeto de opressão, é de extrema importância para a compressão dos fenômenos sociais de qualquer sociedade. A luta pelo poder e supremacia socioeconômico e educacional está intimamente ligada à língua falada pela maioria no mercado, mas dominada por poucos. Como comenta França (2000, in MOURA, 2000, p. 101) "a língua é um processo cultural e também instrumento social do poder concretizado no poder do discurso." O discurso dominador da elite, viabilizada pela língua considerada padrão, serve de instrumento de opressão e detenção à fala das classes desfavorecidas.

Nessa perspectiva, refletir sobre a demora na oficialização de uma língua materna, como é o caso do crioulo haitiano, evidencia discursos, sobretudo o discurso de vozes por vezes silenciadas, isto é, a voz daqueles que, de fato, nunca adotaram como língua materna a do colonizador.

O caso do Crioulo haitiano se revela como um modelo de superação e, ao mesmo tempo, um exemplo de como a supremacia de interesses políticos na sociedade haitiana dita os contornos educacionais e socioeconômicos da população e, consequentemente, a desigualdade de classes sociais existente no Haiti como um todo. Debater essa problemática é imergir, de certa forma, em estudos de caráter pós-colonialistas, cuja crítica questiona o euro-centrismo e dá a voz a produções e discursos dos falantes que estão fora dessa delimitação preconceituosa. Estudar o tripé, qual seja, poder, língua e cultura na sociedade haitiana é descrever como a luta para a independência que continua até hoje, mesmo após 200 anos de independência do país. Como diz Rosa (2007, p. 5), "os movimentos pós-coloniais foram, de fato, motivados no sentido de ocupação do lugar do colonizador e não necessariamente, a inversão da ordem colonial rumo à sua completa negação." Assim, a ideologia do colonizador é assimilada pelo colonizado, mesmo após a independência, as práticas colonialistas geralmente são mantidas. 
Sempre haverá dominante e dominado, a elite e a classe desfavorecida. O Haiti, da mesma forma, segue a mesma lógica. Esta questão, de um modelo imperialista mesmo após a independência do Haiti, será retomada mais detalhadamente em outro tópico.

O presente trabalho objetiva, ainda, demonstrar como a língua é dominada e contornada pelos interesses e práticas políticas da elite de uma sociedade, tornando-se um meio político de dominação e inibidor de oportunidade e espaço sociais. Pretende-se também identificar os desafios que o crioulo haitiano enfrentou no seu processo de oficialização; apontar os interesses políticos que serviram de entrave para tal oficialização; analisar historicamente a evolução da organização do crioulo haitiano enquanto língua e sua importância para a emancipação e representação da identidade cultural do país. Analisar criticamente a relação de poder envolvida no processo de padronização e oficialização de uma língua como discurso dominante sobra classes menos favorecidas.

A metodologia seguida na presente pesquisa é de cunho bibliográfico, com incursões históricas e análises a partir de obras de linguistas e sociólogos que atuam no campo dos estudos linguísticos.

\subsection{A oficialização de uma língua materna: necessi- dade identitária de um povo}

Imergir na filologia do crioulo haitiano não é meramente por uma questão linguística, mas, principalmente para dar voz a aspectos culturais e sociais que estão ligados ao seu uso e expressão quotidianos. Entender que a luta pela sua oficialização não foi por mero capricho ou por revolta anticolonialista apenas, mas por uma necessidade patriótica e identitária. Na verdade, constata-se que no crioulo está grande parte da identidade do povo haitiano (SPEARS et al., 2012).

Vários países, à semelhança do Haiti, lutaram e continuam na luta pela oficialização de sua língua nativa (anexo A). No caso do Haiti e de alguns outros países de fala crioula, a sua utilização quer na escrita ou na fala é um passo importante rumo ao reconhecimento histórico-identitário desses povos. Na verdade, a língua materna é o maior patrimônio restante de uma pátria esfacelada pelos atropelos ditatoriais do país colonizador.

Tomando como exemplo uma premissa alemã para a manutenção de sua identidade étnico-linguística e cultural, como diz Seyferth (1982, p. 113), "um alemão só será reconhecido como tal quando se expressar na sua língua materna", a qual deve ser mantida, conservada e honrada perpetuamente. Como Seyferth (1982, p. 140), ainda mostra no tocante à manutenção da língua materna alemã nas comunidades alemãs no Brasil, sobre as escolas teuto-brasileiras ${ }^{4}$, quando se fala do sistema de ensino que envolve a escola e o lar (Schule und Haus) ${ }^{5}$, a perpetuação do alemão nessas comunidades tradicionais alemães é bem mais real e bem sucedido quando as escolas também ensinam em alemão. Há, portanto, uma complementação entre a língua alemã ensinada em casa pela mãe e a perpetuação da mesma no ambiente escolar.

O "uso oficial", nesse caso da língua alemã, serviu como um complemento ao que se iniciou no lar desde muito cedo. Por conseguinte, quando um aluno inicia seu percurso escolar, acontece uma continuidade e não a agregação de outra língua, desconhecida, usada, por sinal, em poucas situações reais de sua vida. Em outras palavras, reconhecer que "a língua proporciona a própria ideologia étnica" e desempenha um papel importante sobre a própria sobrevivência de um grupo étnico (SEYFERTH, 1982, p. 216).

Historicamente o lugar que hoje é conhecido como Haiti foi o ponto de primeiro contato entre Cristóvão Colombo e os povos que habitavam a ilha, os arwak, em 12 de outubro de 1492. Mais tarde, a ilha receberia o nome de Hispaniola. Mesmo com as encarniçadas lutas com os piratas do Caribe, a ilha ficara sob o domínio espanhol até final do século XVII, quando foi dividida com a França, em 1697. Sob o controle francês e com força de trabalho escravo de povos africanos, a ilha de Santo Domingo francesa se tornou a pérola das Antilhas, como nos disse um haitiano, em janeiro de 2012 em Brasiléia, no Acre: la más bonita de las Antillas. O Haiti era a mais produtiva e a mais lucrativa de todas as possessões francesas. O açúcar era a mercadoria e a força de trabalho era explorada sob o chicote nos canaviais, por uma élite branca, francesa. Menos de cem anos depois do controle de parte da ilha, em 1792, ainda no calor da Revolução

4 Escolas de brasileiros com ascendências alemãs.

5 Seyferth (1982, p. 149) mostra que nas famílias de cultura alemã a mulher enquanto matriarca da família, ela "socializa os filhos e lhes transmite a língua alemã. É a mãe que ensina." Essa missão da mulher teuto-brasileira (alemã-brasileira) de ensinar as bases da língua e cultura alemã aos seus filhos é um fator inibidor para a contratação de casamentos interétnicos, embora seja dividida com as funções de ajudar o marido a cuidar da horta e do jardim. 
Francesa de 1789, ganha corpo um movimento revoltoso formado por escravos (letrados). Em 18 de novembro de 1803, na cidade de Cap-Haïtien, ou Okap, ou Kapayisyen, em Kreyòl, cidade norte do país acontece a batalha final contra as forças militares francesas. É a capitulação da França frente aos já ex-escravos.

Neste contexto revolucionário, algumas escolhas foram feitas e dentre elas, três dialogam diretamente com o sentimento identitário; a bandeira, o nome do lugar e o vernáculo, ou seja, a língua. A bandeira traz o brasão das armas ao centro, no encontro das cores vermelha e azul. $\mathrm{O}$ vermelho representa o sangue e a revolução, enquanto o azul simboliza o povo negro. O nome do lugar remete ao nome antigo em arawak, e em crioulo se escreve Aÿ̈$t i$, que quer dizer lugar de montanhas, montanhoso, alto. Essa é a concepção corrente na tradição haitiana. Isto se confirma quando, "according to tradition, the name Haiti (Ayiti in its official HA spelling) is Amerindian - perhaps Arawak or Carib - and means 'vast land of mountains" (DEGRAFF, 2013, p. 1).

O terceiro elemento escolhido foi a língua. Não tendo uma padronização da língua crioula após a revolução, por decisão política do recém-formado Estado do Haiti, o sistema de ensino seguiu o modelo francês e a língua francesa manteve-se como oficial para os trâmites educacionais, administrativos, burocráticos, estatais, políticos e da religião católica. O crioulo ficou relegado a segundo plano, na perspectiva das questões burocráticas. Entretanto, tornava-se o vernáculo da maioria no dia a dia, a língua materna que as crianças aprendiam primeiro a falar. Nesse contexto se formava e se desenvolvia o crioulo, que mais tarde será idioma reconhecido pelo Estado e um dos elementos da identidade nacional e étnica. Nas palavras de Marques (2012, p. 104), o ensino veio junto com o idioma:

As bases do ensino haitiano foram importadas da França, quando da independência do Haiti, em 1804. Daí o fato de a língua oficial das escolas/ universidades ter sido, durante a maior parte do tempo, o francês e não o kréyol, e do pressuposto de que as instituições de ensino deveriam concentrar-se nas cidades e formar uma elite separada das massas ou das classes populares.

Segundo a autora, o crioulo só passa a ser a língua reconhecida para a escolaridade com a reforma educacional de 1979, porém sem material didático, pois todos se encontravam em francês, o que favorece a defesa do crioulo, por parte de alguns intelectuais, com publicações literárias e gramaticais.

\subsection{A oficialização de uma língua materna e os inte- resses políticos da elite}

Se por um lado a oficialização ou reconhecimento de uma língua materna conecta um povo à sua realidade histórico-identitária, o mesmo não se pode dizer quanto ao interesse da elite, "colonizadora" dominante em todas as sociedades, principalmente nos países que se denominam ex-colônias. Quando pensamos o processo de oficialização de "línguas maternas" faladas em uma colônia, tanto durante quanto após o período desse domínio colonialista, nota-se que tal possibilidade, olhada pela ótica do colonizador, é interpretada como uma iniciativa revolucionária e uma atitude que muitos perigos podem oferecer à hegemonia império-colonial.

Um exemplo que pode elucidar essa realidade é o da carta enviada à corte portuguesa a partir de sua colônia africana, Cabo Verde, conhecida como o anónimo de 1784, no qual se descreve a maneira preconceituosa e que os colonizadores referiam-se ao crioulo como uma forma de rebaixamento do padrão linguístico e cultura do império, sendo uma 'corruptela ridícula' do português, tratando-se de uma ameaça para a unidade do império. (CARREIRA, 1984).

Se por um lado o surgimento do crioulo haitiano uniu os haitianos, escravos, que resolveram lutar pela independência, por outro lado, serviu de ameaça ao sistema colonialista tornando-se uma força motivadora e estratégica para o avanço da revolução e posteriormente a proclamação da independência. Não é coincidência o fato de que o próprio pacto de sangue, pró-independência, conhecido como "Cérémonie du Bois Caïman”, em 14 de agosto de 1791, fosse ratificado com uma oração proferida em crioulo (Créole) pelo sacerdote Dutty Boukman, em rituais do vodu (HANDERSON, 2011, p. 240).

Se uma língua "materna" faz parte da identidade histórica e cultural de um povo, refletindo em suas peculiaridades linguísticas a história da subjugação colonial de uma civilização, ainda que na sua maior parte composta de uma sistematização unicamente oral, é de interesse população falante do Créole, no caso do Haiti, a maioria analfabeta (FIGUEIREDO, 2006), que seu reconheci-

6 Esta cerimônia do vodu, organizada por Dutty Boukman, é considerado no Haiti como o ato de fundação da revolução e da luta pela independência. É o primeiro grande movimento coletivo do Haiti contra a escravatura, assemelhando-se à tomada da Bastilha por parte da França. 
mento e oficialização seja uma realidade. Até porque, de certo modo, toda a sua história e cultura se dá em íntima relação com a sua língua materna. Como comenta (ENNAJI, 2005, p. 24), "de certa forma a pesquisa mostra que a linguagem está intimamente ligada à questão da identidade cultural, e ambos interagem diariamente de várias formas interessantes".

\section{0 caso do crioulo haitiano: de língua de es- cravos a língua oficial}

Como apontado anteriormente, não se sabe ao certo quando o crioulo haitiano começou; o que se imagina é que esta nova língua foi-se formando ao longo do tempo por meio de situações de contato entre os então escravos de origem africana com os colonos franceses, impelidos pela necessidade de comunicação.

Segundo Singler (1996), o crioulo haitiano se desenvolveu entre 1680 e 1740, com a transição para o sistema de plantation - monocultura de exportação por meio de latifúndios de força de trabalho escrava. A economia deu um salto com a importação de escravos da África para trabalhar no cultivo da cana de açúcar e a população da ilha aumentou significativamente. Essa mudança, segundo Lefebvre (1998 apud CAISSE, 2012), favoreceu, em certa medida, a formação do crioulo haitiano, "[...] uma comunidade linguística multilíngue com falantes de línguas mutuamente incompreensíveis - o que gerou a necessidade de um sistema de comunicação comum - e que têm pouco contato direto com falantes do superstrato, neste caso, o francês" (CAISSE, 2012, p. 12).

Assim, o crioulo haitiano foi se formando ao longo do tempo por meio de situações de contato entre os então escravos de origem africana com os colonos franceses, impelidos pela necessidade de comunicação. Vale ressaltar, como indica Wladimir Valler Filho (2007), que $o$ francês falado pelos colonizadores daquela época era o francês da região da Normandia, diferindo bastante do francês moderno. Além disso, o que torna mais difícil fazer um levantamento histórico do crioulo é a ausência de documentos, textos escritos nessa e sobre essa língua, já que o francês era a língua da elite, do colonizador, o dominador, enquanto o crioulo era a língua dos escravos. O texto considerado mais antigo foi escrito entre $1782 \mathrm{e}$ 1783 (RODRIGUES, 2008, p. 90), um bilhete de amor de um amante que assassinara a amada,
Moi étais à la case à moi; moi étais après préparer cassave à moi; Zéphir venir trouver moi, li dit que li aimer moi, et qu'il voulait que moi aimer li tout. Moi répondre li que moi déjà aimer mon autre et que moi pas capable d'aimer deux. Li dit moi, que li mériter mieux amour à moi que matelot à li. Moi répondre li, que li capable de mériter li mieux, mais que li pas te gagner li encore. Li dit moi que li va gagner li, et tout de suite li faire moi violence[...] Ah, toi connais comment li fort! Juger si gagner faute à moi! Le ciel témoin, cher dombo, de l'innocence et de fidélité à moi!

Pode-se perceber a semelhança com o francês, todavia desde o momento em que o texto foi escrito, mudanças ocorreram no Haiti, desde questões linguísticas, religiosas até as decisões políticas. Avançando no tempo veremos que o reconhecimento dessa língua só viria quase duzentos anos após a independência do Haiti. Não é nossa intenção neste texto aprofundar questões de origem e história do crioulo haitiano, no entanto é necessário um breve panorama das questões de política linguística em relação às duas línguas oficiais no Haiti.

Na senda das pesquisas de Caisse (2012), por muitos anos o crioulo haitiano não tinha uma ortografia, era majoritariamente uma língua falada, com pouco registro escrito, sem uma ortografia unificada. Nesse sentido, somente na década de 1940 começou-se a propor uma ortografia para o crioulo. Em 1975, com um movimento de revalorização da língua materna dos haitianos que, a partir de uma reforma educacional no país, iria ser ensinada nas escolas, surgiram várias propostas de ortografia o que gerou muita polêmica. Finalmente, cessando a polêmica em torno do assunto, "o $\mathrm{CH}$ adquiriu uma ortografia semioficial em 1980".

Mesmo com a instituição do francês como língua oficial no país desde a independência, até a constituição de 1987 - que elege também o crioulo como língua oficial - nunca a população haitiana adotou de fato o francês como sua língua. Ao contrário, segundo o linguista haitiano Dejean (1983), o francês é uma língua estrangeira no Haiti, tanto para o haitiano menos favorecido, sem estudo que vê o francês como a língua dos brancos colonizadores, como para uma elite escolarizada, com instrução que vê o francês como a língua da França ou de outros países. Ainda de acordo com Dejean (1983, p. 190), "nos dois casos, são conscientes do fato de que falar francês é característico do não-pertencimento à identidade étnica ou nacional haitiana".

De acordo com Rodrigues (2008), o crioulo rece- 
beu a sua primeira grafia oficial em 1980, fruto de um movimento iniciado na década de 1940, quando pesquisadores tomaram consciência das gravidades do analfabetismo no país e, ao mesmo tempo, se conscientizaram de que o crioulo não era um dialeto do francês, mas uma língua diferente, e a partir disso propuseram uma grafia que correspondesse à sua fonética própria. A partir dessa constatação, Pradel Pompilus, um linguista haitiano e Paul Berry, educador estadunidense que vivera por alguns anos no Haiti, apresentaram uma proposta de mudança ortográfica com o objetivo de aproximar a fonética do crioulo ao francês por meio da escrita e, para isso, propuseram quatro princípios, sendo o primeiro a facilitação para quem lesse francês pudesse ler o crioulo - isso para não perder o apoio da elite francófona no Haiti. O segundo propunha que, a partir do letramento em crioulo, o leitor pudesse ler o francês; o terceiro objetivava proporcionar a leitura de cartazes, jornais, etc. em francês aos crioulófonos e o quarto, ensejava que a ortografia facilitasse a alfabetização dos crioulófonos monolíngues analfabetos. Sobre o tema, narra Rodrigues (2008, p. 109), explicando a relação foneticista

Com o princípio inicial sendo mantido, temos então uma ortografia de base fonológica. Diferentemente do francês, no crioulo haitiano tudo o que se escreve se pronuncia, tudo o que se escreve corresponde a um som. Esta correspondência tão estreita entre o oral e o escrito, torna a ortografia do crioulo muito simples de ser dominada: o crioulo pode ser facilmente lido e escrito.

A instituição do crioulo não foi, contudo, uma conquista rápida, da noite para o dia. O seu espaço de atuação oficial ainda se encontra em definição, entretanto possui forte base legal, desde a Constituição do País. Concernente à educação, uma legislação vem sendo construída ao longo das últimas quatro décadas, como a Lei sobre o planejamento da alfabetização, que data de 1961, ou a Lei Orgânica que versa sobre a elevação da língua crioula à condição instrumento de ensino nas escolas, juntamente com o francês, promulgada em 1979 pelo Departamento de Educação Nacional, além de um Decreto que visa organizar o sistema educativo, com a finalidade de criar um espaço de igualdade de oportunidades para todos e, ao mesmo tempo, possibilitar uma reflexão sobre a cultura haitiana.

As quatro últimas décadas viram em todos os territórios crioulófonos de expressão francesa um grande movimento de valorização da língua vernácula. Quatro etapas se discernem nesta corrente reivindicatória: (1) o reconhecimento do crioulo como língua; (2) a adoção do crioulo como símbolo da identidade cultural e nacional; (3) o reconhecimento do crioulo como instrumento literário; (4) a utilização do crioulo na administração e no ensino (RODRIGUES, 2008, p. 68).

\subsection{Produções de descentralização do poder sobre a língua}

A decisão política de reconhecimento gradativo do crioulo haitiano não se deu gratuita ou voluntariamente. Pelo contrário, como apontamos anteriormente, as primeiras manifestações pela luta por reconhecimento vêm desde os anos de 1940. Em 1975, temos a publicação do primeiro romance em crioulo, intitulado Dezafi, do escritor Franketiene, consubstanciando uma luta que já se encontrava travada por intelectuais como Félix Morisseau-Leroy, ainda nos anos de 1960, em defesa do crioulo. Assim, a década de 1970 assistiu a uma difusão de obras escritas em crioulo, dando cada vez mais visibilidade nacional em prol de seu reconhecimento.

\footnotetext{
Neste período também aparecem no Haiti numerosas obras que vão dar um impulso importante à literatura crioula, ainda que as dificuldades econômicas do Haiti não permitissem uma difusão muito grande dessas obras. Ao lado de Franketienne, aparecem obras de Morisseau-Leroy, Célestin-Mégie, G. Castera, J.M. Etièn, Carrié Paultre (RODRIGUES, 2008, p. 105).
}

Nesse sentido, pode-se considerar que os intelectuais haitianos tiveram grande importância no processo de reconhecimento político do crioulo enquanto veículo (língua) de comunicação e, consequentemente, elemento aglutinador da identidade haitiana.

Esse erguer e posicionar da parte dos escritores haitianos é um grito de identidade, levando o saber a lutar contra o poder, de modo que a identidade seja resgatada. Como comenta Foucault (2005, p. 44), "todo sistema de educação é uma maneira política de manter ou modificar a apropriação dos discursos [...] permite ou impede as linhas que estão marcadas pela distância, oposições e lutas sociais”.

Nesse processo, um dos acontecimentos mais importantes é a Constituição de 1987, na qual tornam co-oficiais o crioulo e o francês. Dessa forma, dota-se o crioulo de um instrumento legal perante a comunidade nacional e, mais importante, no interior de suas fronteiras com a veiculação de livros nesta língua, além da sua difusão por meio dos documentos oficiais, escolarização e tradução de obras de outras línguas.

Mesmo que ainda não goze de igualdade em relação ao francês nos trâmites burocráticos e administra- 
tivos, o crioulo haitiano ganha cada vez mais o status de língua oficial e, dessa forma, sai da marginalidade para o reconhecimento. Até porque essa relação é marcada por uma luta de poderes. Com diz Ennaji (2005, p. 25), “em algumas situações bilíngues, a segunda língua é tão forte que provoca a perda da língua materna. A perda da identidade linguística é um resultado da adoção da língua do colonizador em setores vitais da vida".

No caso haitiano, vemos exatamente o contrário. Apesar de ser a língua falada por quase a totalidade da população, ou seja, pouco mais de $5 \%$ domina o francês (RODRIGUES, 2008; DEGRAFF, 2013; MARQUES, 2012), o seu reconhecimento é marcado por lutas políticas e sociais. Embora, a língua materna seja responsável por grande parte do conteúdo cultural e identitário de um povo (MERCER et al., 1979 apud ENNAJI, 2005).

Certamente o documento mais importante a esse respeito é a Constituição do país, que no final da década de 1980 oficializou o uso do crioulo em trâmites burocráticos na esfera governamental.

A Constituição haitiana de 1987 tornou co-oficiais o francês e o crioulo, obrigando o Estado haitiano a publicar todos os documentos oficiais nessas duas línguas. No momento, as leis, os códigos, os formulários, as peças administrativas ainda são redigidos quase que exclusivamente em francês (RODRIGUES, 2008, p. 5).

O crioulo haitiano foi, durante mais de três séculos, uma língua viva, falada por um número considerável de pessoas, mas que por falta de reconhecimento político por parte do Estado haitiano, não contou com sua organização formal no plano linguístico acadêmico. Mesmo sendo uma língua corrente, de fato e de direito, o seu reconhecimento só foi possível por meio da luta militante de intelectuais, no entanto o que a lei diz não é, na prática, o que as pessoas fazem.

\section{Independência e colonialismo de mãos da- das: o Haiti hoje}

O colonialismo francês, tanto antes quanto depois da independência, abalou grandemente os três pilares da cultura e da identidade Haitiana, a saber, os lakous ${ }^{7}$, o

7 Historicamente, o Lakou se refere ao aglomerado de habitações nas quais residem famílias haitianas, bem como a múltipla geração das tradicionais famílias haitianas, o qual é proeminente na cultura haitiana. Inicialmente, os membros de um lakou trabalhavam cooperativamente e proviam uns vodu e o Créole. No caso dos Lakous e sua relação com o Créole, Santiago (2013, p. 139) comenta,

Nos lakous, as cerimônias se organizam em crioulo haitiano, língua materna, ao lado da língua francesa. O francês é uma imposição do grupo dominante e dos antigos colonos, consagrada como oficial pela Constituição haitiana em 1987, na Ditadura Duvalier, que sufocou os três pilares da cultura haitiana: o lakou, o vodou e o kreòle (crioulo haitiano). O crioulo é a língua mais falada por todos os haitianos, $\mathrm{e}$ o francês é a língua de uma elite que se espera, tenha um nível de estudos avançado.

Ao se referir ao francês como a língua da elite politica e que tem mais oportunidades de educação, automaticamente a face da desigualdade provocada por esse não reconhecimento da língua crioula enquanto símbolo da história e identidade haitiana emerge de forma clara na sociedade haitiana. $\mathrm{O}$ colonialismo francês e sua reprodução através dos governos ditatoriais haitianos posteriores mexeram profundamente com a identidade histórica e cultural haitiana. De certa maneira, olhando pelo viés da identidade nacional, o Haiti ainda hoje vive e luta contra a invasão e dominação francesa. Como comenta Fishman (1999 apud ENNAJI, 2005, p. 23), identidade é a relação dinâmica entre a herança histórica ancestral, com os componentes (tradição oral, literatura, crenças etc.) e a sua linguagem, o qual marca o nascimento de uma identidade cultural especifica. No caso haitiano, respectivamente, os lakous, o Créole e o vodu.

No tocante à relação entre o Créole e o vodu, como símbolos da identidade haitiana, mostra como a sua inibição subjugou a identidade haitiana negando a sua história e cultura,

A negação da cultura haitiana, com a diabolização da religião Vodu e a proibição nas escolas da língua Crioulo, produziu um país com duas representações: francesa e crioula, de matriz europeia e de matriz africana, católica e praticante do vodu, letrada e oral (analfabeta), considerando-se que a grande maioria da população haitiana é, até nossos dias analfabeta; a fala e a escrita em francês sendo restrita a uma minoria. Neste sentido, pode-se dizer que o Haiti sempre viveu uma situação de diglossia e de tensões e negociações entre a língua do colonizador e a língua do povo, entre o francês e o crioulo. (PARISE, 2014, p. 75).

Como afirma Hurbon (1988, p. 79),

o Vodu, como religião e cultura por excelência das classes populares no país, ele é visto como

aos outros de recursos financeiros e outras formas de recursos. (EDMOND, 2007) 
alguma coisa de superstição primitiva ao mesmo tempo em que seus simpatizantes são oprimidos pelas classes dominantes. É importante salientar que o Vodu, predominante nas comunidades rurais no Haiti, muitas vezes é taxado como a causa de atraso do país por aqueles que quiseram transfundir nas veias dos moradores dessas comunidades uma missão civilizadora via catolicismo e protestantismo, as quais sempre defenderam que essa seria a única maneira pela qual o povo haitiano poderia se tornar "desenvolvido", "moderno" e "civilizado".

Essa representação preconceituosa da religião e língua tradicional haitiana, na visão de Beauvoir (2010 apud HANDERSON, 2011, p. 238), "é devida principalmente ao cristianismo e às potências estrangeiras como França, Estados Unidos e Espanha".

$\mathrm{Na}$ verdade, no Haiti, o colonizado passou a ser colonizador, após a independência. Ao tentar criar uma identidade de estado e nação para os haitianos, acabaram por subjuga-la mais ainda. Pois, na implementação de uma política de estado independente acabaram imitando, por uma imposição ideológica e discursiva colonialista, o modelo de civilização europeia, mais especificamente o francês. Em outras palavras, foram impelidos a usarem máscaras brancas sobre suas peles (quase) negras. (FANON, 2008).

O que se percebe é que os mais de duzentos anos de independência do Haiti ainda não foram suficientes para o país se libertar definitivamente dessa "francofilia" que continua fazendo do país uma colônia contemporânea. O que se torna, do ponto de vista político mais intrigante, é que essa neocolonização é protagonizada pelo discurso político europeu através da própria elite haitiana. Vê-se, que por meio de discursos ideológicos e políticos, pela relação de poder opressivo da elite sobre as classes desfavorecidas, o próprio haitiano, que detém tais práticas, tornou-se também um colonizador, negando sua identidade revolucionária e negociando seu orgulho histórico de língua, pensamento e cultura.

\section{Considerações Finais}

O Haiti é um país que mesmo após duzentos anos de independência, continua lutando pela libertação de seu colonizador. Embora militarmente seja reconhecido como um estado independente, política, cultural e linguisticamente apresenta características de uma colônia, o qual repete em suas atitudes políticas e linguísticas, o discurso e a ideologia euro-centrista, reproduzindo a dominação colonizadora em vários aspectos de sua sociedade.

O crioulo haitiano surgiu num momento histórico definido e recente, o contexto do processo colonizador e, por isso, talvez explique o interesse de muitos pesquisadores em buscar compreender as suas origens e desenvolvimento. Nem por isso será fácil encontrar uma explicação sobre o seu surgimento, especialmente pela falta de documentos escritos e mesmo a seu respeito. Dessa forma, enveredar por esse terreno pode ser perigoso, pois é arriscado fazer afirmações concernentes a esse processo no sentido de dar uma resposta pronta e acabada, visto que se tornou objeto de muitas controvérsias, uma vez que não é possível precisar a sua genealogia de maneira satisfatória.

Ao longo da sua formação, o crioulo haitiano passou por um longo processo de marginalização no sentido de não ser reconhecido como língua, apesar de ser falado pela quase totalidade dos haitianos como língua materna, já que o francês é uma segunda língua e a sua aquisição se dá após os haitianos terem aprendido o crioulo. Outro aspecto importante é o fato de o francês figurar como a língua do colonizador e, consequentemente, um traço diacrítico, operando como sinal de contraste que demarca espaços de poder. A diferenciação que é feita a partir do idioma francês por um haitiano indica que este faz parte de uma pequena elite da sociedade, ou seja, aquele que teve acesso à escolarização, que é predominantemente em francês e em escolas majoritariamente privadas, o que pode indicar a condição socioeconômica das pessoas e o lugar social de cada um.

A luta pelo reconhecimento do Créole como símbolo da identidade haitiana continua até hoje, mesmo após sua oficialização juntamente com a constituição de 1987. Ainda os intelectuais pró-Créole buscam um lugar para ela no sistema educacional e político do país. Essa luta que hoje vê no horizonte uma luz mais forte de esperança de emancipação real, já foi mais renhida no passado, quando os mulatos, haitianos, assumiram o poder após a independência e reproduziram a ideologia colonizadora em seu próprio país, contra seus próprios irmãos.

A oficialização do Créole haitiano não resolveu o problema da desigualdade social do país e nem equiparou a elite racial e política às classes desfavorecidas. Mas deu voz à identidade histórica e linguística do país e tem servido para manter um dos maiores símbolos da cultura haitiana em vida, o vodu. 
Provavelmente essa luta pela libertação e descolonização continuará renhida até que o Haiti político e elitizado encontre e reconheça suas raízes históricas e linguísticas, e se desvencilhe da ideologia colonizadora europeia, e na relação de poder e saber, não dê lugar ao preconceito linguístico ou racial, mas promova a igualdade.

Para que o poder político sirva unicamente para tornar o povo haitiano, novamente, não uma pérola entre as colônias francesas, mas um estado reconhecido pela sua postura anticolonialista e promovedora de igualdade e reconhecimento histórico, cultural e linguístico no cenário mundial.

\section{Referências}

CAISSE, Peter Thomas et al. A vitalidade linguística dos crioulos do Haiti e da Luisiana: os limites da política e das atitudes linguísticas. 2012. Dissertação (Mestrado) - Programa de Pós-Graduação em Linguística, Universidade Estadual de Campinas, Campinas, 2012.

CARREIRA, António. O crioulo de Cabo Verde: surto e expansão. Lisboa: ICALP, 1984.

DEGRAFF, Michel. Kreyòl Ayisyen, or Haitian Créole ('Créole French'). Disponível em: <http://web.mit.edu/ linguistics/people/faculty/degraff/degraff2007hc-ccs. pdf $>$. Acesso em: 09 fev. 2013.

DEJEAN, Yves. Diglossia revisited: french and créole. Word, Haiti, v. 34, n. 3, p. 189-213, 1983.

EDMOND, Yanique M.; RANDOLPH, Suzanne M.; RICHARD, Guylaine L. The lakou system: a cultural, ecological analysis of mothering in rural Haiti. Journal of Pan African Studies, v. 2, n. 1, p. 19-32, 2007. Disponível em: <http://www.jpanafrican.com/docs/vol2nol/ TheLakouSystem.pdf>. Acesso em: 29 mar. 2015.

ENNAJI, Moha. Multilingualism, cultural identity, and education in Morocco. Berlim: Springer Science \& Business Media, 2005.

FANON, Frantz. Los condenados de la Tierra. México: Fondo de Cultura Económica, 2001.

FANON, Frantz. Pele negra máscaras brancas. Salvador: EDUFBA, 2008.

FIGUEIREDO, Euridice. O Haiti: história, literatura, cultura. Revista Brasileira do Caribe, Goiânia, v. 6, n. 12, jan./jun, 2006.

FOUCAULT, Michel. A ordem do discurso. 12. ed. São Paulo: Loyola, 2015.

GARCÍA, Ofelia; ZAKHARIA, Zeena; OTCU, Bahar
(Ed.). Bilingual community education and multilingualism: beyond heritage languages in a global city. Reino Unido: Multilingual Matters, 2012.

GENTINI, Alfredo Martin; PROPSERE, Renel. O vodu no universo simbólico haitiano. Universitas: Relações Internacionais, Brasília, v. 11, n. 1, p. 73-81, 2013. doi: 10.5102/uri. v11i1. 2408

HANDERSON, Joseph. Religiosidade afrodiaspórica como elemento constitutivo do Estado-Nação. Identidade!, São Leopoldo, v. 16, n. 2, p. 237-248, 2011.

HURBON, Laennec. O deus da resistência negra: o vodu haitiano. São Paulo: Paulinas, 1987.

MARQUES, Pâmela Marconatto. Outras estórias haitianas: educação, resistência e esperança no mais desconhecido dos países latino-americanos. Revista Brasileira de Estudos Latino-Americanos, Florianópolis, v. 2, n. 1, p. 99-112, jun. 2012.

MOURA, Clóvis. Dicionário da escravidão negra no Brasil. São Paulo: Edusp, 2004.

MOURA, Denilda (Org.). Língua e ensino: dimensões heterogêneas. Maceió: Edufal, 2000.

PARISE, Normelia M. Literatura e oralidade no Haiti. Revista do GT de Literatura Oral e Popular da ANPOLL, Londrina, n. 17, p. 72-87, jan./jul. 2014.

RODRIGUES, Luiz Carlos Balga. Francês, crioulo e vodu: a relação entre língua e religião no Haiti. 2008. 259 f. Tese (Doutorado) - Programa de Pós-Graduação em Letras, Universidade Federal do Rio de Janeiro, Rio de Janeiro, 2008.

ROSA, Renata de Melo. A construção da desigualdade no Haiti: experiências históricas e situações atuais. Universitas: Relações Internacionais, Brasília, v. 4, n. 2, p. 0-24, 2007. doi: 10.5102/uri. v4i2. 160

ROTBERG, Robert I. (Ed.). Haiti renewed: political and economic prospects. Washington: Brookings Institution Press, 2001.

SANTIAGO, Adriana (Ed.). Haití por sí: la reconquista de la independencia robada. Fortaleza: Adital-Agência de Informação Frei Tito para América Latina, 2013.

SEMEDO, José. Enriquecimento do léxico da língua caboverdiana: variante de Santiago. 2006. Monografia (Graduação) - Curso de Licenciatura em Estudos Caboverdianos e Portugueses, Instituto Superior de Ensino, Santiago, 2006.

SEYFERTH, Giralda. Nacionalismo e identidade étnica: a ideologia germanista e o grupo étnico teuto-brasileiro numa comunidade do Vale do Itajaí. Florianópolis: FCC, 1982. 
SOARES, Carlos Eugênio Líbano; GOMES, Flávio. Sedições, haitianismo e conexões no Brasil escravista: outras margens do atlântico negro. Novos Estudos CEBRAP, São Paulo, n. 63, p. 131-144, jul. 2002.

SPEARS, Arthur. K. et al. The haitian créole language: history, structure, use, and education. Lanham, MarylandUSA: Lexington Books, 2012.
VALLER FILHO, Wladimir. O Brasil e a crise haitiana: a cooperação técnica como instrumento de solidariedade e de ação diplomática. Brasília: FUNAG, 2007.

VASCONCELOS, Alex Donizete. Haiti: identidades e representação. Revista Urutágua, Maringá, n. 20, p. 38$51,2010$.

ANEXO A:

LISTA PAÍSES DE LÍNGUA MATERNA DENOMINADA “CRIOULO"
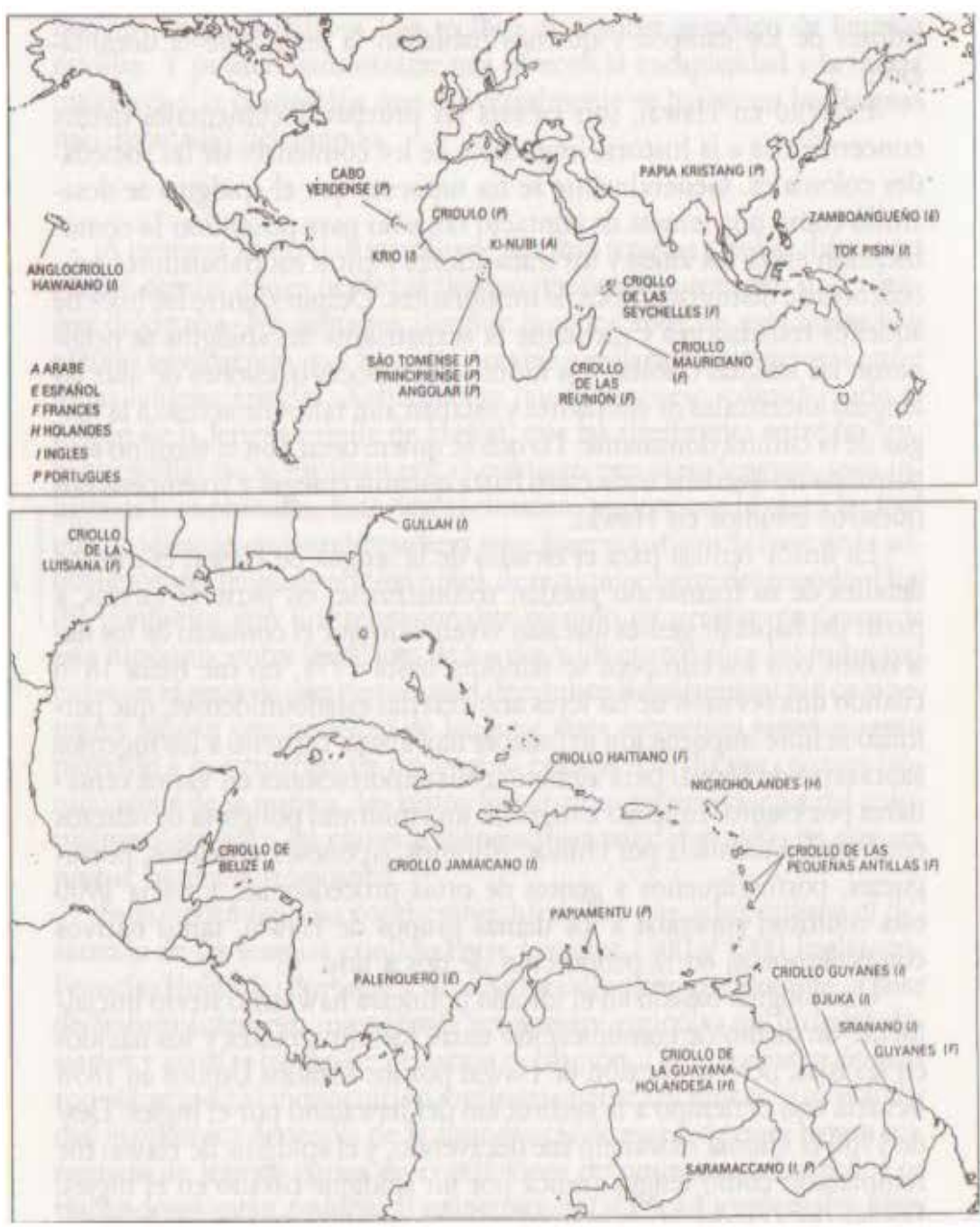

Fonte: BICKERTON, Derek, apud SEMEDO, José. Enriquecimento do Léxico da Língua Caboverdiana - variante de Santiago. Monografia apresentada ao curso de Licenciatura em Estudos Caboverdianos e Portugueses, sob orientação do Dr. Daniel Medina. Instituto Superior de Ensino. Praia, Santiago, 2006. 